\title{
Prognosis and endocrine therapy selection for patients with low hormone receptor-positive breast cancer following neoadjuvant chemotherapy: A retrospective study of 570 patients in China
}

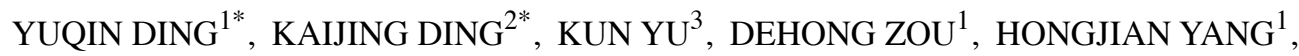 \\ XIANGMING $\mathrm{HE}^{1}$, WENJU MO ${ }^{1}$, XINGFEI YU ${ }^{1}$ and XIAOWEN DING ${ }^{1}$ \\ ${ }^{1}$ Department of Breast Surgery, Zhejiang Cancer Hospital, Hangzhou, Zhejiang 310022; ${ }^{2}$ Department of Child Psychology, \\ Zhejiang University Affiliated Mental Health Center, Hangzhou, Zhejiang 310013; ${ }^{3}$ Department of Thyroid \\ Breast Surgery, Zhejiang Provincial People's Hospital, Hangzhou, Zhejiang 310014, P.R. China
}

Received May 1,2019; Accepted September 26, 2019

DOI: $10.3892 / \mathrm{ol} .2019 .11033$

\begin{abstract}
The 2010 American Society of Clinical Oncology guidelines have reduced the immunohistochemistry cut-off value for determining estrogen receptor b positivity from 10 to $1 \%$ of stained cells in breast cancer. In clinical practice, low-hormone receptor positive (low $\mathrm{HR}+$ ) tumors are classified in the luminal subtype, although they exhibit aggressive features and poor prognosis. Information regarding the prognosis of patients with breast cancer following treatment with optimal endocrine therapy and neoadjuvant chemotherapy (NAC) is currently lacking. In the present study, the differences in clinical characteristics and survival of patients with breast cancer were compared among those with low and high HR+ breast cancer who received NAC. Furthermore, the effects of different types of endocrine therapies on the prognosis of patients with breast cancer were compared. The study population comprised patients with primary breast cancer who were treated at the Zhejiang Cancer Hospital between January, 2007 and December, 2017. Patients were divided into three groups based on the results of immunohistochemistry: HR+ (positive staining $>10 \%$ ), HR- (positive staining $<1 \%$ ) and
\end{abstract}

Correspondence to: Dr Xiaowen Ding, Department of Breast Surgery, Zhejiang Cancer Hospital, 1 Banshan Road, Hangzhou, Zhejiang 310022, P.R. China

E-mail: dingxw@zjcc.org.cn

*Contributed equally

Abbreviations: AJCC, American Joint Committee on Cancer; DFS, disease-free survival; ER, estrogen receptor; HER-2, human epidermal growth factor receptor 2; HR, hormone receptor; NAC, neoadjuvant chemotherapy; NG, nuclear grade; pCR, pathological complete response; PR, progesterone receptor; OS, overall survival; TNBC, triple negative breast cancer

Key words: breast cancer, estrogen receptor, progesterone receptor, neoadjuvant chemotherapy, pathologic complete response low HR+ (positive staining 1-10\%). The low HR+ group was further divided into three subgroups according to the different endocrine therapies administered: Tamoxifen, aromatase inhibitor or no treatment. Among the 570 patients included in the present study, 60 (10.53\%) patients had low HR+ tumors. With a median follow-up of 48.98 months, patients with low $\mathrm{HR}+$ tumors had reduced survival rates compared with those with HR+ tumors. Furthermore, the pathologic complete response rate (pCR) of patients with low $\mathrm{HR}+$ was comprised between $\mathrm{pCR}$ from patients with $\mathrm{HR}+$ and $\mathrm{pCR}$ from patients with HR- following NAC treatment. In addition, no significant difference in the overall prognosis was observed among patients with low $\mathrm{HR}+$ following treatment with different endocrine therapies. Subsequently, patients in the low HR+ group were more likely to benefit from NAC compared with patients in the $\mathrm{HR}+$ group. Intensive endocrine therapy may therefore improve the prognosis of patients with breast cancer and low HR+; however, further investigation is required.

\section{Introduction}

The status of hormone receptors (HRs), including estrogen receptor (ER) and progesterone receptor (PR), in breast cancer is crucial for predicting patient responsiveness to endocrine therapy $(1,2)$. The majority of breast tumors $(\sim 70 \%)$ highly express hormone receptor $(\mathrm{HR}+)$. Patients with $\mathrm{HR}+$ tumors have better disease-specific survival and overall survival (OS) compared with those with HR-negative (HR-) tumors $(1,2)$.

Previously, HR positivity was assessed using immunohistochemistry (IHC) scoring with a $\geq 10 \%$ cutoff value for nuclear staining of tumor epithelial cells (3). However, the 2010 guidelines from the College of American Pathologists and American Society of Clinical Oncology changed the IHC cut-off value for determining HR positivity from $10 \%$ to $1 \%$ of stained cells (4). This has led to the creation of a subclass of low $\mathrm{HR}+(1-10 \%)$ tumors in breast cancer. This new subclass has been reported to have beneficial impact on patients' response to antiestrogen therapy $(2,5,6)$.

It has been demonstrated that, although triple-negative breast cancer (TNBC) is more sensitive to chemotherapy than 
$\mathrm{HR}+$ breast cancer, its prognosis remains poor (7). Previous studies reported that low HR-positive tumors (low HR+) have more aggressive features and poorer prognosis compared with high HR+ tumors $(6,8)$. Numerous studies have reported that tumors with ER expression $<10 \%$ are likely to exhibit biological behaviors similar to those from ER negative (ER-) tumors $(5,6,9)$. However, to the best of our knowledge, studies comparing the neoadjuvant chemotherapy (NAC) response between low ER+ breast cancer tumors and other types of breast cancer remain limited $(10,11)$. In addition, there is no consistency in the choice of endocrine therapy for the treatment of low $\mathrm{HR}^{+}$breast cancer.

The present study compared low HR+ tumors with HR+ and HR- tumors in order to understand the clinical characteristics and prognosis of patients with breast cancer following NAC treatment. To do so, the pathological response to NAC in these three types of tumors was determined. The effect of various endocrine treatment regimens on the prognosis of patients with breast cancer and low $\mathrm{HR}^{+}$expression was subsequently investigated.

\section{Materials and methods}

Patient selection. The present study was approved by the Ethics Committee of Zhejiang Cancer Hospital. The medical records of 1,194 patients with stages IIA-IIIC primary breast cancer who received NAC at the Zhejiang Cancer Hospital in China between January, 2007 and December, 2017 were examined retrospectively. All patients enrolled had undergone a core needle biopsy and subsequent surgery prior to and following NAC treatment. Patients with incomplete or inconsistent IHC data were excluded. Other exclusion criteria were: i) Patients with stage IV breast cancer, bilateral breast cancer, inflammatory breast cancer or diagnosed with another primary cancer; ii) patients who did not complete the standard NAC regimen; and iii) patients who received radiation therapy prior to surgery. The pathological stage of tumors was assessed according to the American Joint Committee on Cancer (AJCC) 8th Staging System (12). The intensity of HR nuclear staining was divided into three groups and defined as negative, low positive and positive for $<1 \%, 1-10 \%$ and $>10 \%$ of nuclear staining, respectively. The following conditions were defined as low HR+: Low ER+/low PR+, low ER+/PR-, and ER-/low PR+. The therapeutic response of patients was investigated according to alterations in tumor size that was determined by radiographic assessment or clinical examination, as documented in the patient medical records. The pathologic complete response (pCR) was defined as the absence of invasive tumor in the breast resection specimen and regional lymph nodes following surgery.

Patients had received NAC under various regimens. The most common were anthracycline and cyclophosphamide followed by paclitaxel (EC-T, daily injection, 21 days per cycle, 8 cycles total) (13) or a combination of three drugs (Paclitaxel/anthracycline/cyclophosphamide, TEC, daily injection, 21 days per cycle, 6 cycles total) (14). Trastuzumab was routinely administered to patients with human epidermal growth factor receptor-2 (HER-2) positivity as an anti-HER therapy. Tamoxifen or aromatase inhibitors were used as postoperative adjuvant endocrine therapeutic agents for patients with HR+ tumors.
Statistical analysis. The expression data of HR staining from IHC analysis were divided into three groups ( $\mathrm{HR}+$, low $\mathrm{HR}+$ and HR-) and analyzed as categorical variables. $\chi^{2}$ test was used to examine the association between HR expression and the clinicopathological factors of patients. Kaplan-Meier analysis was performed to investigate the disease-free survival (DFS) and overall survival (OS) of patients and a log-rank test was conducted to determine significant differences. Patient features with $\mathrm{P}<0.1$ in univariate analysis were used for multivariate analysis, which was used to determine differences in prognosis between the $\mathrm{HR}+$, low $\mathrm{HR}+$ and HR- groups. Forward conditional logistic regression was also performed. $\mathrm{P}<0.05$ was considered to indicate a statistically significant difference. All statistical analyses were performed using SPSS software version 24 (IBM Corp.).

\section{Results}

Clinical and pathological characteristics of tumors. The median age of the enrolled patients was 50 years (range, 21-75 years), and $9.1 \%$ of patients were $\leq 35$ years old. In the present study, $301(52.8 \%)$ patients had HR+ tumors, 209 (36.7\%) patients had HR- tumors and 60 (10.5\%) patients had low HR+ tumors (Table I). The median follow-up duration for the 570 patients included in this analysis was 48.98 months (range, 22.37-93.73 months). The rate of patients who successfully completed the follow up was $92 \%(n=525) ; 45$ patients discontinued contact during follow-up.

Overall, HR+ tumors were detected more frequently in premenopausal women $(60.13 \%)$ compared with other subtypes (low $\mathrm{HR}+, 45.0 \%$ and HR-, 47.4\%; $\mathrm{P}=0.006$ ). A total of 537 (94.2\%) patients had invasive ductal carcinoma, and among the other patients, 14 (2.5\%) had invasive lobular carcinoma, $11(1.9 \%)$ had invasive micropapillary carcinoma, four $(0.7 \%)$ had mucinous breast carcinoma and four $(0.7 \%)$ had metaplastic breast carcinoma. The majority of patients had stage II $(59.8 \%)$ or III $(40.2 \%)$ disease. In addition, there were $374(65.6 \%)$ T2 tumors and $331(58.1 \%)$ N1 tumors based on the National Comprehensive Cancer Network (NCCN) guidelines (15). Furthermore, the 11 (3.7\%) patients who had nuclear grade (NG) I tumors were included in the HR+ group. Compared with HR+ tumors, low HR+ tumors were not significantly different with regards to the histopathological type, AJCC stage and T stage. In addition, compared with $\mathrm{HR}+$ tumors, HR- and low HR+ tumors exhibited higher NG (NG III of 20 and $25.4 \%$, respectively vs. $15.6 \%$; $\mathrm{P}<0.001$ ), upregulated Ki-67 expression (83.3 and $89.0 \%$, respectively vs. 67.4\%; $\mathrm{P}<0.001$ ), increased HER-2 expression (40.0 and $46.9 \%$, respectively vs. $20.6 \%$; $\mathrm{P}<0.001)$ and higher $\mathrm{N}$ stage (N2/N3 stages of 33.3 and $24.4 \%$, respectively vs. $21.3 \%$; $\mathrm{P}=0.046)$. However, there was no difference between the clinicopathological characteristics of HR- tumors and low HR+ tumors $(\mathrm{P}>0.05)$.

A total of $424(74.4 \%)$ patients presented a positive clinical response (complete response and partial response) to NAC based on the Response Evaluation Criteria In Solid Tumors (Table I). The rates of CR for HR+, low HR+ and HR- tumors were $10.6,15.0$ and $22.5 \%$, respectively; however, no statistically significant difference between the three groups was observed $(\mathrm{P}=0.219)$. 
Table I. Comparison of clinicopathological characteristics according to HR expression level in patients with primary breast cancer.

\begin{tabular}{|c|c|c|c|c|c|c|c|}
\hline \multirow{2}{*}{$\begin{array}{l}\text { Patient } \\
\text { characteristics }\end{array}$} & \multicolumn{2}{|c|}{ HR positive } & \multicolumn{2}{|c|}{ Low HR positive } & \multicolumn{2}{|c|}{ HR negative } & \multirow[b]{2}{*}{ P-value } \\
\hline & Number & $\%$ & Number & $\%$ & Number & $\%$ & \\
\hline Total & 301 & 52.81 & 60 & 10.53 & 209 & 36.67 & \\
\hline \multicolumn{8}{|l|}{ Age, years } \\
\hline Median & 48 & & 51 & & 50 & & \\
\hline$\leq 35$ & 30 & 10.0 & 8 & 3.3 & 14 & 6.7 & 0.22 \\
\hline$>35$ & 271 & 90.0 & 52 & 86.7 & 195 & 93.3 & \\
\hline \multicolumn{8}{|l|}{ Menopausal status } \\
\hline Premenopausal & 181 & 60.1 & 27 & 45.0 & 99 & 47.4 & 0.01 \\
\hline Postmenopausal & 120 & 39.9 & 33 & 55.0 & 110 & 52.6 & \\
\hline \multicolumn{8}{|l|}{ Histology } \\
\hline IDC & 279 & 92.7 & 58 & 96.7 & 200 & 95.7 & 0.23 \\
\hline Others & 21 & 7.0 & 2 & 3.3 & 8 & 3.8 & \\
\hline Missing & 1 & 0.3 & - & - & 1 & 0.5 & \\
\hline \multicolumn{8}{|l|}{ Nuclear grade } \\
\hline $\mathrm{I}$ & 11 & 3.7 & - & - & - & - & $<0.001$ \\
\hline II & 97 & 32.2 & 9 & 15.0 & 36 & 17.2 & \\
\hline III & 47 & 15.6 & 12 & 20.0 & 53 & 25.4 & \\
\hline Missing & 146 & 48.5 & 39 & 65.0 & 120 & 57.4 & \\
\hline \multicolumn{8}{|l|}{ AJCC stage } \\
\hline IIA & 69 & 22.9 & 9 & 15.0 & 33 & 15.8 & 0.09 \\
\hline IIB/IIA & 174 & 57.8 & 34 & 56.7 & 132 & 63.2 & \\
\hline IIIB/IIIC & 58 & 19.3 & 17 & 28.3 & 44 & 21.1 & \\
\hline \multicolumn{8}{|l|}{ Ki-67 expression } \\
\hline$\leq 14 \%$ & 80 & 26.6 & 6 & 10.0 & 17 & 8.1 & $<0.001$ \\
\hline$>14 \%$ & 203 & 67.4 & 50 & 83.3 & 186 & 89.0 & \\
\hline Missing & 18 & 6.0 & 4 & 6.7 & 6 & 2.9 & \\
\hline \multicolumn{8}{|l|}{ Her- 2 expression } \\
\hline Negative & 200 & 66.4 & 32 & 53.3 & 97 & 46.4 & $<0.001$ \\
\hline Equivocal & 37 & 12.3 & 4 & 6.7 & 14 & 6.7 & \\
\hline Positive & 62 & 20.6 & 24 & 40.0 & 98 & 46.9 & \\
\hline Missing & 2 & 0.7 & - & - & - & - & \\
\hline \multicolumn{8}{|c|}{ Therapeutic evaluation } \\
\hline $\mathrm{cCR}$ & 32 & 10.6 & 9 & 15.0 & 47 & 22.5 & 0.22 \\
\hline $\mathrm{cPR}$ & 192 & 63.8 & 41 & 68.3 & 103 & 49.3 & \\
\hline $\mathrm{cSD}$ & 75 & 24.9 & 9 & 15.0 & 53 & 25.4 & \\
\hline $\mathrm{cPD}$ & 2 & 0.7 & 1 & 1.7 & 6 & 2.9 & \\
\hline \multicolumn{8}{|l|}{ T stage } \\
\hline $\mathrm{T} 0 / 1$ & 26 & 8.6 & 8 & 13.3 & 16 & 7.7 & 0.10 \\
\hline $\mathrm{T} 2$ & 211 & 70.1 & 37 & 61.7 & 126 & 60.3 & \\
\hline $\mathrm{T} 3$ & 26 & 8.6 & 7 & 11.7 & 44 & 21.1 & \\
\hline $\mathrm{T} 4$ & 37 & 12.3 & 8 & 13.3 & 23 & 11.0 & \\
\hline Missing & 1 & 0.3 & - & - & - & - & \\
\hline \multicolumn{8}{|l|}{$\mathrm{N}$ stage } \\
\hline No & 60 & 19.9 & 6 & 10.0 & 38 & 18.2 & 0.05 \\
\hline N1 & 177 & 58.8 & 34 & 56.7 & 120 & 57.4 & \\
\hline N2 & 37 & 12.3 & 10 & 16.7 & 28 & 13.4 & \\
\hline N3 & 27 & 9.0 & 10 & 16.7 & 23 & 11.0 & \\
\hline
\end{tabular}

IDC, invasive ductal carcinoma; AJCC, American Joint Committee on Cancer; HER-2, human epidermal growth factor receptor-2; HR, hormone receptor; $\mathrm{cCR}$, clinical complete response, disappearance of all target lesions; cPR, clinical partial response, $\geq 30 \%$ decrease in the sum of diameters of target lesions; cPD, clinical progression of disease, $\geq 20 \%$ increase in the sum of diameters of target lesions; cSD, clinical stable disease, neither sufficient shrinkage to qualify for PR nor sufficient increase to qualify for PD. 


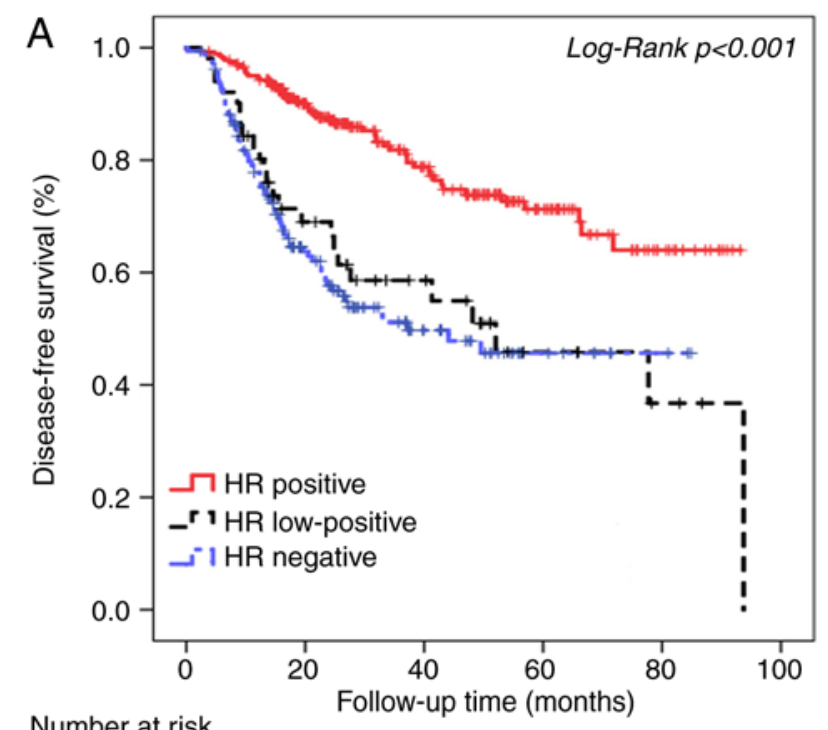

$\begin{array}{lllllll}\text { Number at risk } & & & & & \\ \text { HR+ } & 318 & 219 & 119 & 54 & 17 & 0 \\ \text { Low-HR+ } & 60 & 33 & 20 & 8 & 4 & 0 \\ \text { HR- } & 192 & 89 & 35 & 12 & 4 & 0\end{array}$

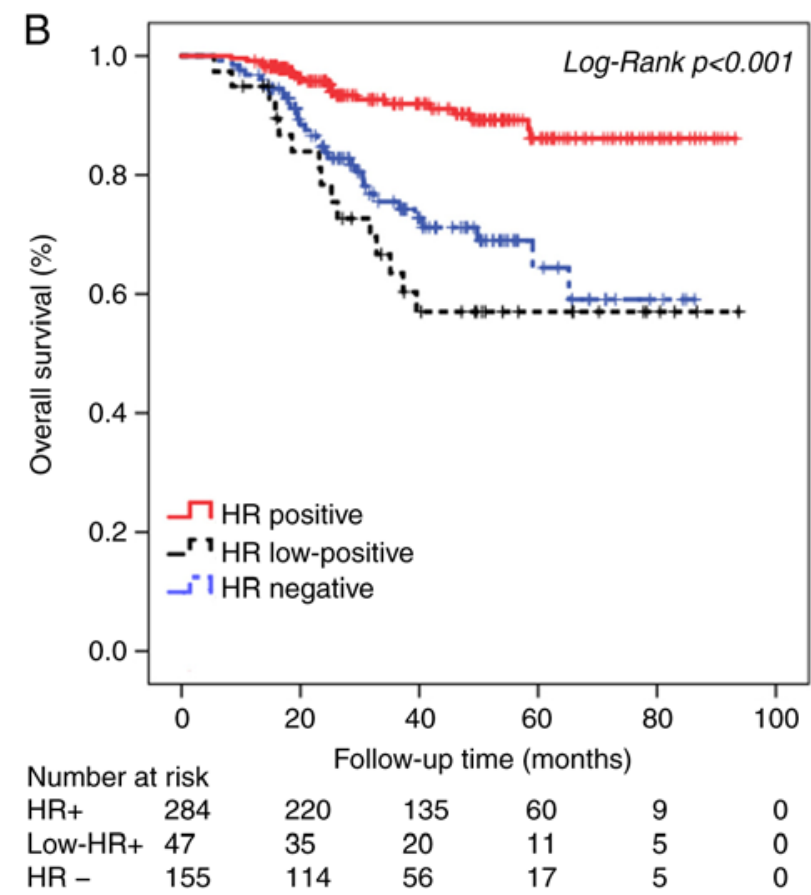

Figure 1. Kaplan-Meier curves of survival outcomes among patients with three different levels of HR expression in the primary tumor. (A) Distant recurrence-free survival. (B) Overall survival. HR, hormone receptor.

Survival analysis outcomes. Univariate analysis for DFS and $\mathrm{OS}$ in the HR+, HR- and low HR+ tumors groups was performed using Kaplan-Meier survival analysis. The survival curve for low $\mathrm{HR}+$ tumors was located between that of $\mathrm{HR}^{+}$ and $\mathrm{HR}^{-}$tumors. Patients with low HR+ tumors had worse DFS and OS (Fig. 1) compared with patients with HR+ tumors, which was similar to that of HR-patients. The median DFS was $72.71 \pm 2.42,53.57 \pm 5.97$ and $48.18 \pm 3.16$ months for the HR+, low HR+ and HR- groups, respectively $\left(\chi^{2}=43.59\right.$; $\mathrm{P}<0.001)$. The median OS was $85.11 \pm 1.73,63.92 \pm 5.92$ and 65.24 \pm 3.17 months for the HR+, low HR+ and HR-groups,
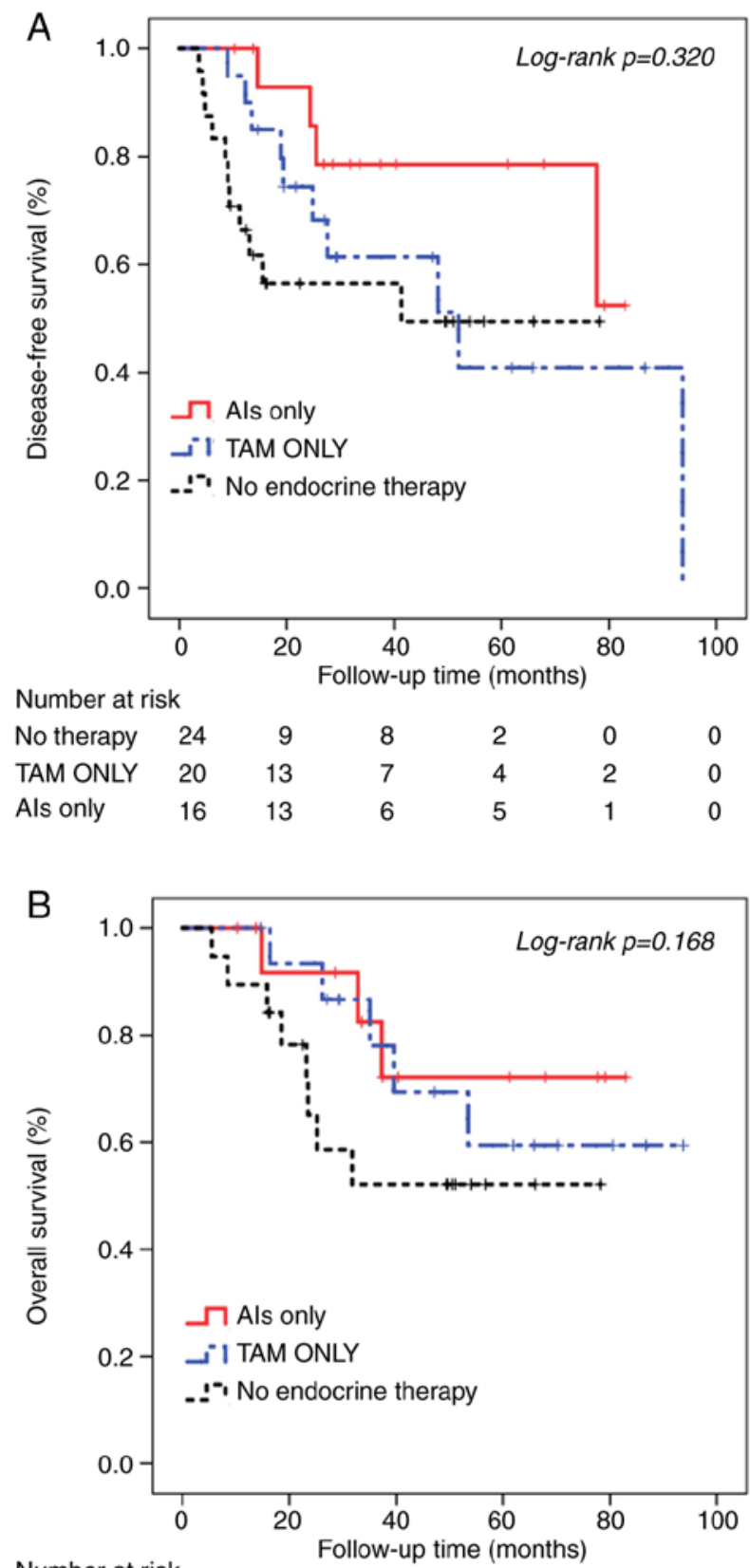

\begin{tabular}{lrrrrrr}
\multicolumn{6}{l}{ Number at risk } & \multicolumn{6}{c}{ Follow } \\
No therapy & 19 & 13 & 8 & 2 & 0 & 0 \\
TAM ONLY & 16 & 14 & 8 & 6 & 2 & 0 \\
Als only & 14 & 11 & 6 & 5 & 1 & 0
\end{tabular}

Figure 2. Kaplan-Meier curves of survival outcomes among patients treated with different endocrine therapies. (A) Distant recurrence-free survival. (B) Overall survival.

respectively $\left(\chi^{2}=28.31 ; \mathrm{P}<0.001\right)$. The 5-year DFS for patients with HR+, low HR+ and HR- tumors was 71.3, 45.9 and $45.7 \%$, respectively, and the 5-year OS for patients with $\mathrm{HR}+$, low $\mathrm{HR}+$ and HR- tumors was $86.2,57.0$ and $64.4 \%$, respectively.

The multivariate Cox proportional hazards model was used to determine differences in prognosis between the HR+, low HR+ and HR- tumors groups, excluding potential survival confounding factors, including age, menopausal status, histological type, NG, AJCC staging, and tumor and lymph node staging. As presented in Table II, patients with HR+ tumors had significantly better DFS and OS compared with patients 
Table II. Cox regression analysis of patient survival outcomes according to HR expression level in patients with primary breast cancer.

A, Disease-free survival

\begin{tabular}{|c|c|c|c|c|c|c|}
\hline \multirow[b]{2}{*}{ HR status } & \multicolumn{3}{|c|}{ Univariate Analysis } & \multicolumn{3}{|c|}{ Multivariate Analysis } \\
\hline & Hazard Ratio & $95 \% \mathrm{CI}$ & P-value & Hazard Ratio & $95 \% \mathrm{CI}$ & P-value \\
\hline Positive & 1 & & $<0.001$ & 1 & & $<0.001$ \\
\hline Low-positive & 2.60 & $1.60-4.24$ & 0.006 & 2.82 & $2.10-3.86$ & 0.018 \\
\hline Negative & 3.04 & $2.13-4.35$ & $<0.001$ & 2.94 & $1.75-5.00$ & $<0.001$ \\
\hline
\end{tabular}

B, Overall survival

\begin{tabular}{|c|c|c|c|c|c|c|}
\hline \multirow[b]{2}{*}{ HR status } & \multicolumn{3}{|c|}{ Univariate Analysis } & \multicolumn{3}{|c|}{ Multivariate Analysis } \\
\hline & Hazard Ratio & $95 \% \mathrm{CI}$ & P-value & Hazard Ratio & $95 \% \mathrm{CI}$ & P-value \\
\hline Positive & 1 & & $<0.001$ & 1 & & 0.001 \\
\hline Low-positive & 4.57 & $2.34-8.92$ & $<0.001$ & 4.76 & $4.11-5.56$ & 0.019 \\
\hline Negative & 3.28 & $1.87-5.74$ & $<0.001$ & 4.76 & $2.08-11.11$ & $<0.001$ \\
\hline
\end{tabular}

HR, hormone receptor; CI, confidence interval.

with low HR+ tumors (DFS, $\mathrm{P}=0.018$; OS, $\mathrm{P}=0.019$ ). In addition, patients with HR- tumors had similar DFS and OS to patients with low HR+ tumors (data not shown).

Among the 60 patients with low HR+ tumors, 24 (40.0\%) patients did not receive postoperative adjuvant endocrine therapy. The remaining 36 patients underwent different regimens of endocrine therapy: 20 patients $(33.3 \%)$ received tamoxifen and 16 patients $(26.7 \%)$ were administered an aromatase inhibitor. Univariate Kaplan-Meier analysis was performed of the low HR+ tumors group stratified according to the different endocrine therapies administered. The results demonstrated that patients who did not receive endocrine therapy had poorer DFS (45.44 \pm 7.20 months, Fig. 2A) and OS (50.21 77.31 months, Fig. 2B) compared with patients who received endocrine therapy. Among patients who received endocrine therapy, patients who received treatment with the aromatase inhibitor exhibited better DFS (68.42 \pm 6.68 months) compared with patients treated with tamoxifen $(55.79 \pm 9.21$ months). However, there were no significant differences in the DFS and OS between the three groups $\left(\mathrm{DFS}, \chi^{2}=2.28, \mathrm{P}=0.320 ; \mathrm{OS}, \chi^{2}=3.56, \mathrm{P}=0.168\right.$ ).

\section{Discussion}

The present study evaluated the clinicopathological characteristics and prognosis of patients with low HR+ tumors compared with patients with $\mathrm{HR}+$ and HR- tumors. The results demonstrated that $10.5,52.8$ and $36.7 \%$ of patients had low $\mathrm{HR}+, \mathrm{HR}+$ and HR- tumors. As demonstrated in previous studies, the clinical and biological features of low HR+ tumors were similar to those of HR-tumors, which presented aggressive biological behaviors $(5,6)$. In addition, patients with low HR+ tumors of advanced stages presented an increased incidence of aggressive phenotype. With regards to NG and the expression of $\mathrm{Ki}-67$ and HER-2, low HR+ tumors exhibited moderate characteristics compared with the other two cohorts. The survival curve of patients with low HR+ tumors was located between that of patients with HR+ and HR-tumors, which indicated poorer DFS and OS compared with patients with HR+ tumors. It has been reported that increased activity of the growth factor signaling pathways and upregulated Ki-67 expression could be associated with the aggressiveness of low HR+ tumors (16-19).

Numerous studies have investigated the concept of low HR+ tumors $(9,10,17)$; however, the efficacy of NAC against low $\mathrm{HR}+$ tumors remains to be determined. In the majority of cases, this subtype are often not considered in the clinical treatment of tumors, as patients are divided into two categories: HR+ and HR-. The present study identified a group of low HR+ tumors with a distinct phenotype that were sensitive to NAC. Guarneri et al (20) demonstrated that, although the overall prognosis of TNBC is poor compared with that of breast cancer luminal subtype, TNBC has a higher pCR rate following NAC treatment. Furthermore, Carey et al (21) reported that there was no difference in prognosis between patients with TNBC subtype and non-TNBC subtypes who achieved pCR after NAC treatment. However, the prognosis of TNBC subtype is significantly worse compared with non-TNBC subtypes following non-pCR after NAC. compared with non-triple-negative ones. The CREATE-X studies also reported that in certain subgroups of breast cancer, including HER-2 positive and TNBC types, increased pCR rate following NAC treatment could benefit patient survival (7). The present study evaluated the efficacy of chemotherapy in low HR+, HR+ and HR-tumors following NAC treatment. The results demonstrated that the $\mathrm{pCR}$ rates 
of the three groups following NAC treatment were 10.63 (HR+), 15.00 (low HR+) and 22.49\% (HR-). In addition, the pCR rate of the low $\mathrm{HR}+$ group was slightly increased compared with the HR+ group. Regarding the response to $\mathrm{NAC}$, the low $\mathrm{HR}^{+}$cohort appeared to have potentially benefited from postoperative enhanced adjuvant chemotherapy regimens, including 6-8 cycles of capecitabine.

To the best of our knowledge, only a few studies have determined whether different endocrine therapy regimens: Tamoxifen, aromatase inhibitor or combined treatment with ovarian function suppression, affect the prognosis of patients with low HR+ tumors. The findings from the present study were consistent with results from Yi et al (11) that demonstrated that tumors with an ER-positivity rate of 1-9\% do not significantly benefit from endocrine therapy. However, the DFS and OS of patients who received endocrine therapy had notably improved compared with non treated patients (11). The St Gallen 2005 guidelines for the primary therapy of early breast cancer (3) suggested the three following categories for scoring ER status: i) Endocrine responsive, with strong ER expression; ii) endocrine response uncertain, with low ER expression; and iii) endocrine nonresponsive, with no ER expression. These guidelines suggested that the endocrine responsive group should receive endocrine therapy and adjuvant chemotherapy; however, the distinction between 'endocrine responsive' and 'endocrine response uncertain' was not determined in the guidelines. It has been suggested that the loss of PR could be considered as a marker of aberrant growth factor signaling and was proposed as being associated with endocrine resistance (22).

A recent meta-analysis reported that the recurrence rate of breast cancer continued to rise over 5-20 years following treatment and after 5 years of endocrine therapy, whereas the cumulative risk may vary between 10 and $41 \%$ (23). The BIG19-8 (24) and ATAC (25) clinical studies have confirmed that enhanced or prolonged endocrine therapy might be beneficial for the survival of patients with a recurrence high risk. Furthermore, the NCCN guidelines (version 3.2018) (26) recommended that some genomic assays could have a prognostic value for screening patients with a high risk of recurrence 0-10 years after surgery, including the 21-gene Oncotype Dx assay (27), 70-gene MammaPrint assay (28), PAM50 (Prosigna) (29), EPclin (12 gene, EndoPredict) $(30,31)$ and the Breast Cancer Index (32). Dowsett et al (33) reported a simpler predictive tool called CTS5 for investigating endocrine therapy-enhancing strategies that is based on the analysis of the clinicopathological characteristics of patients with breast cancer. The results from the present study suggested that the prognostic benefits of postoperative adjuvant endocrine therapy may be restricted for low $\mathrm{HR}^{+}$patients; however, with the rational use of the aforementioned effective tools to predict the risk of recurrence following standard treatments in patients with high risk and poor prognosis, including patients with low HR+ tumors, enhanced endocrine therapy may be beneficial to patient survival.

This study presented certain limitations. This study was a retrospective analysis, and the type of adjuvant treatment was not administered on a randomized basis. Furthermore, patient classification was not made according to treatment with trastuzumab, since only $49.49 \%$ (98/198) of patients overexpressing
HER-2- received trastuzumab due to drug availability and unfavorable health care policies.

In conclusion, the present study demonstrated that patients with breast cancer and low HR+ tumors presented similar clinicopathological characteristics to patients with HR- tumors. Furthermore, patients with low HR+ tumors exhibited poorer survival compared with patients with $\mathrm{HR}+$ tumors. In addition, no significant difference in the survival between patients with low HR+ tumors and those with HR- tumors was reported. These findings suggested that patients with low HR+ tumors may benefit from postoperative intensive adjuvant chemotherapy and endocrine therapy. Further investigation is required to determine the underlying mechanism of low HR+ breast cancer. In addition, prospective clinical studies are urgently needed to validate the importance of enhanced adjuvant therapy for the prognosis of patients with low HR+ breast cancer.

\section{Acknowledgements}

Not applicable.

\section{Funding}

The present study was funded by the Zhejiang Medical and Health Science and Technology Project, Zhejiang Provincial Department of Health (grant no. 2017KY019).

\section{Availability of data and material}

The datasets used and/or analyzed during the present study are available from the corresponding author on reasonable request.

\section{Authors' contributions}

YD designed the study, analyzed and interpreted the data, prepared figures, wrote the manuscript and supervised the study. KD analyzed and interpreted the data. XD and DZ developed the methodology and revised the manuscript. HY provided technical support, assisted in developing the methodology and revised the manuscript. XH and WM prepared tables and figures, performed database research and analyzed and interpreted the data. KY and XY provided and prepared histological sections from patients with breast cancer. All authors read and approved the final version of the manuscript.

\section{Ethics approval and consent to participate}

The present study was approved by the Administration Ethics Committee of Zhejiang Cancer Hospital and conducted in accordance with the Principles of Helsinki Declaration. Patient consent was not required because of the retrospective nature of the study.

\section{Patient consent for publication}

Not applicable.

\section{Competing interests}

The authors declare that they have no competing interests. 


\section{References}

1. Early Breast Cancer Trialists' Collaborative Group (EBCTCG): Effects of chemotherapy and hormonal therapy for early breast cancer on recurrence and 15-year survival: An overview of the randomised trials. Lancet 365: 1687-1717, 2005.

2. Waks AG and Winer EP: Breast cancer treatment: A review. JAMA 321: 288-300, 2019.

3. Goldhirsch A, Glick JH, Gelber RD, Coates AS, Thürlimann B and Senn HJ; Panel members: Meeting highlights: International expert consensus on the primary therapy of early breast cancer 2005. Ann Oncol 16: 1569-1583, 2005.

4. Hammond ME, Hayes DF, Dowsett M, Allred DC, Hagerty KL, Badve S, Fitzgibbons PL, Francis G, Goldstein NS, Hayes M, et al: American Society of Clinical Oncology/College Of American Pathologists guideline recommendations for immunohistochemical testing of estrogen and progesterone receptors in breast cancer. J Clin Oncol 28: 2784-2795, 2010.

5. Gloyeske NC, Dabbs DJ and Bhargava R: Low ER+ breast cancer: Is this a distinct group? Am J Clin Pathol 141: 697-701, 2014.

6. Raghav KP, Hernandez-Aya LF, Lei X, Chavez-Macgregor M, Meric-Bernstam F, Buchholz TA, Sahin A, Do KA, Hortobagyi GN and Gonzalez-Angulo AM: Impact of low estrogen/progesterone receptor expression on survival outcomes in breast cancers previously classified as triple negative breast cancers. Cancer 118: 1498-1506, 2012.

7. Masuda N, Lee SJ, Ohtani S, Im YH, Lee ES, Yokota I, Kuroi K, Im SA, Park BW, Kim SB, et al: Adjuvant capecitabine for breas cancer after preoperative chemotherapy. N Engl J Med 376 : 2147-2159, 2017.

8. Reddy SM, Barcenas CH, Sinha AK, Hsu L, Moulder SL, Tripathy D, Hortobagyi GN and Valero V: Long-term survival outcomes of triple-receptor negative breast cancer survivors who are disease free at 5 years and relationship with low hormone receptor positivity. Br J Cancer 118: 17-23, 2018.

9. Prabhu JS, Korlimarla A, Desai K, Alexander A, Raghavan R, Anupama C, Dendukuri N, Manjunath S, Correa M, Raman N, et al: A majority of low (1-10\%) ER positive breast cancers behave like hormone receptor negative tumors. J Cancer 5: 156-165, 2014.

10. Landmann A, Farrugia DJ, Zhu L, Diego EJ, Johnson RR, Soran A, Dabbs DJ, Clark BZ, Puhalla SL, Jankowitz RC, et al: Low estrogen receptor (ER)-positive breast cancer and neoadjuvant systemic chemotherapy: Is response similar to typical ER-positive or ER-negative disease? Am J Clin Pathol 150: 34-42, 2018.

11. Yi M, Huo L, Koenig KB, Mittendorf EA, Meric-Bernstam F, Kuerer HM, Bedrosian I, Buzdar AU, OSymmans WF, Crow JR, et al: Which threshold for ER positivity? a retrospective study based on 9639 patients. Ann Oncol 25: 1004-1011, 2014.

12. Amin MB, Edge S, Greene F, Byrd DR, Brookland RK, Washington MK, Gershenwald JE, Compton CC, Hess KR, Sullivan DC, et al: Eds.: AJCC cancer staging manual. New York, 2017

13. von Minckwitz G, Raab G, Caputo A, Schütte M, Hilfrich J, Blohmer JU, Gerber B, Costa SD, Merkle E, Eidtmann H, et al: Doxorubicin with cyclophosphamide followed by docetaxel every 21 days compared with doxorubicin and docetaxel every 14 days as preoperative treatment in operable breast cancer: The GEPARDUO study of the german breast group. J Clin Oncol 23: 2676-2685, 2005.

14. Bines J, Earl H, Buzaid AC and Saad ED: Anthracyclines and taxanes in the neo/adjuvant treatment of breast cancer: Does the sequence matter? Ann Oncol 25: 1079-1085, 2014.

15. Gradishar WJ, Anderson BO, Balassanian R, Blair SL, Burstein HJ, Cyr A, Elias AD, Farrar WB, Forero A, Giordano SH, et al: NCCN guidelines insights: Breast cancer, Version 1.2017. J Natl Compr Canc Netw 15: 433-451, 2017.

16. Prat A, Cheang MC,Martin M,Parker JS, Carrasco E, Caballero R, Tyldesley S, Gelmon K, Bernard PS, Nielsen TO and Perou CM: Prognostic significance of progesterone receptor-positive tumor cells within immunohistochemically defined luminal A breast cancer. J Clin Oncol 31: 203-209, 2013

17. Bae SY, Kim S, Lee JH, Lee HC, Lee SK, Kil WH, Kim SW, Lee JE and Nam SJ: Poor prognosis of single hormone receptorpositive breast cancer: Similar outcome as triple-negative breast cancer. BMC Cancer 15: 138, 2015.
18. Cancello G,Maisonneuve P,Rotmensz N, Viale G,Mastropasqua MG, Pruneri G, Montagna E, Iorfida M, Mazza M, Balduzzi A, et al: Progesterone receptor loss identifies Luminal B breast cancer subgroups at higher risk of relapse. Ann Oncol 24: 661-668, 2013.

19. Braun L, Mietzsch F, Seibold P, Schneeweiss A, Schirmacher P, Chang-Claude J, Peter Sinn H and Aulmann S: Intrinsic breast cancer subtypes defined by estrogen receptor signalling-prognostic relevance of progesterone receptor loss. Mod Pathol 26 : 1161-1171, 2013.

20. Guarneri V, Broglio K, Kau SW, Cristofanilli M, Buzdar AU, Valero V, Buchholz T, Meric F, Middleton L, Hortobagyi GN and Gonzalez-Angulo AM: Prognostic value of pathologic complete response after primary chemotherapy in relation to hormone receptor status and other factors. J Clin Oncol 24: 1037-1044, 2006.

21. Carey LA, Dees EC, Sawyer L, Gatti L, Moore DT, Collichio F, Ollila DW, Sartor CI, Graham ML and Perou CM: The triple negative paradox: Primary tumor chemosensitivity of breast cancer subtypes. Clin Cancer Res 13: 2329-2334, 2007.

22. Cui X, Schiff R, Arpino G, Osborne CK and Lee AV: Biology of progesterone receptor loss in breast cancer and its implications for endocrine therapy. J Clin Oncol 23: 7721-7735, 2005.

23. Pan H, Gray R, Braybrooke J, Davies C, Taylor C, McGale P, Peto R, Pritchard KI, Bergh J, Dowsett M, et al: 20-Year risks of breast-cancer recurrence after stopping endocrine therapy at 5 Years. N Engl J Med 377: 1836-1846, 2017.

24. Breast International Group (BIG) 1-98 Collaborative Group; Thurlimann B, Keshaviah A, Coates AS, Mouridsen H, Mauriac L, Forbes JF, Paridaens R, Castiglione-Gertsch M, Gelber RD, et al: A comparison of letrozole and tamoxifen in postmenopausal women with early breast cancer. N Engl J Med 353: 2747-2757, 2005.

25. Cuzick J, Sestak I, Baum M, Buzdar A, Howell A, Dowsett M and Forbes JF; ATAC/LATTE investigators: Effect of anastrozole and tamoxifen as adjuvant treatment for early-stage breast cancer: 10-year analysis of the ATAC trial. Lancet Oncol 11: 1135-1141, 2010.

26. Bevers TB, Helvie M, Bonaccio E, Calhoun KE, Daly MB, Farrar WB, Garber JE, Gray R, Greenberg CC, Greenup R, et al: Breast cancer screening and diagnosis, Version 3.2018, NCCN clinical practice guidelines in oncology. J Natl Compr Canc Netw 16: 1362-1389, 2018.

27. Paik S, Shak S, Tang G, Kim C, Baker J, Cronin M, Baehner FL, Walker MG, Watson D, Park T, et al: A multigene assay to predict recurrence of tamoxifen-treated, node-negative breast cancer. $\mathrm{N}$ Engl J Med 351: 2817-2826, 2004.

28. van 't Veer LJ, Dai H, van de Vijver MJ, He YD, Hart AA, Mao M, Peterse HL, van der Kooy K, Marton MJ, Witteveen AT, et al: Gene expression profiling predicts clinical outcome of breast cancer. Nature 415: 530-536, 2002

29. Sestak I, Dowsett M, Zabaglo L, Lopez-Knowles E, Ferree S, Cowens JW and Cuzick J: Factors predicting late recurrence for estrogen receptor-positive breast cancer. J Natl Cancer Inst 105: 1504-1511, 2013

30. Filipits M, Rudas M, Jakesz R, Dubsky P, Fitzal F, Singer CF, Dietze O, Greil R, Jelen A, Sevelda P, et al: A new molecular predictor of distant recurrence in ER-positive, HER2-negative breast cancer adds independent information to conventional clinical risk factors. Clin Cancer Res 17: 6012-6020, 2011

31. Buus R, Sestak I, Kronenwett R, Denkert C, Dubsky P, Krappmann K, Scheer M, Petry C, Cuzick J and Dowsett M: Comparison of endopredict and EPclin with oncotype DX recurrence score for prediction of risk of distant recurrence after endocrine therapy. J Natl Cancer Inst 108: 2016.

32. Jerevall PL, Ma XJ, Li H, Salunga R, Kesty NC, Erlander MG, Sgroi DC, Holmlund B, Skoog L, Fornander T, et al: Prognostic utility of HOXB13:IL17BR and molecular grade index in early-stage breast cancer patients from the Stockholm trial. Br J Cancer 104: 1762-1769, 2011.

33. Dowsett M, Sestak I, Regan MM, Dodson A, Viale G, Thürlimann $\mathrm{B}$, Colleoni $\mathrm{M}$ and Cuzick $\mathrm{J}$ : Integration of clinical variables for the prediction of late distant recurrence in patients with estrogen receptor-positive breast cancer treated with 5 years of endocrine therapy: CTS5. J Clin Oncol 36: 1941-1948, 2018.

This work is licensed under a Creative Commons Attribution-NonCommercial-NoDerivatives 4.0 International (CC BY-NC-ND 4.0) License. 